\title{
Solvates of Sildenafil Saccharinate. A New Host Material
}

\author{
Rahul Banerjee, Prashant M. Bhatt and Gautam R. Desiraju* \\ School of Chemistry, University of Hyderabad, Hyderabad 500 046, India. \\ E-mail:gautam_desiraju@yahoo.com
}

\section{Supplementary Material (ESI)}

(14 pages)

(i) ORTEP diagrams (50\% probability), DSC and TGA of sildenafil saccharinate (SS) apohost and its solvates.

(ii) 2D packing of the hexagonal cavities in the solvates of SS.

(iii) VTPXRD of sildenafil saccharinate dihydrate. 


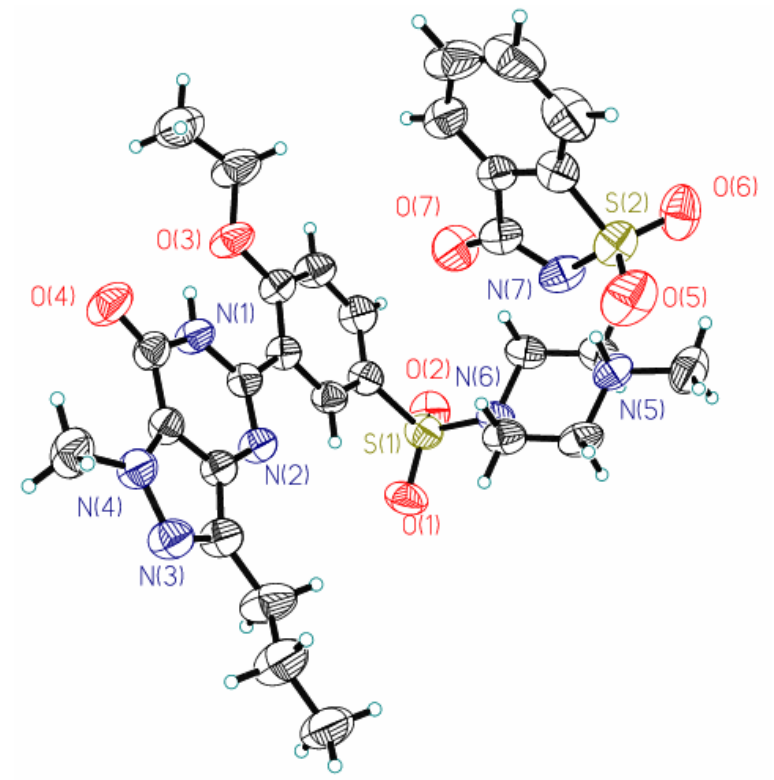

Figure 1. ORTEP diagram of SS apohost

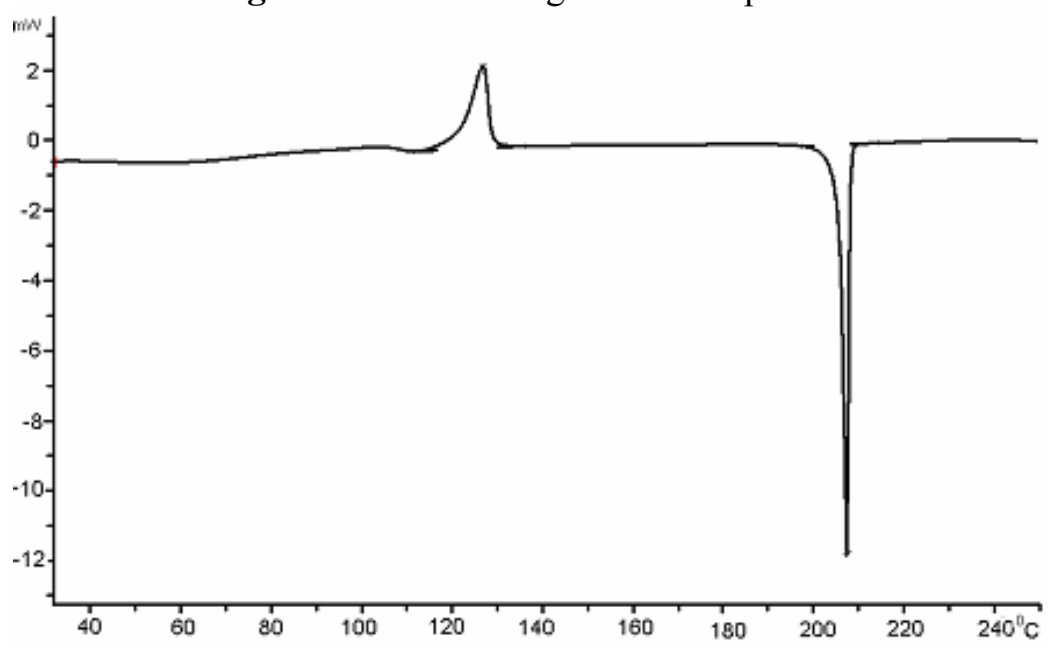

Figure 2. DSC traces of the ground SS recorded at a heating rate of $5{ }^{\circ} \mathrm{C} \mathrm{min}^{-1}$.Note the exothermic region at $120^{\circ} \mathrm{C}$ showing the phase transformation amorphous SS $\rightarrow$ crystalline SS.

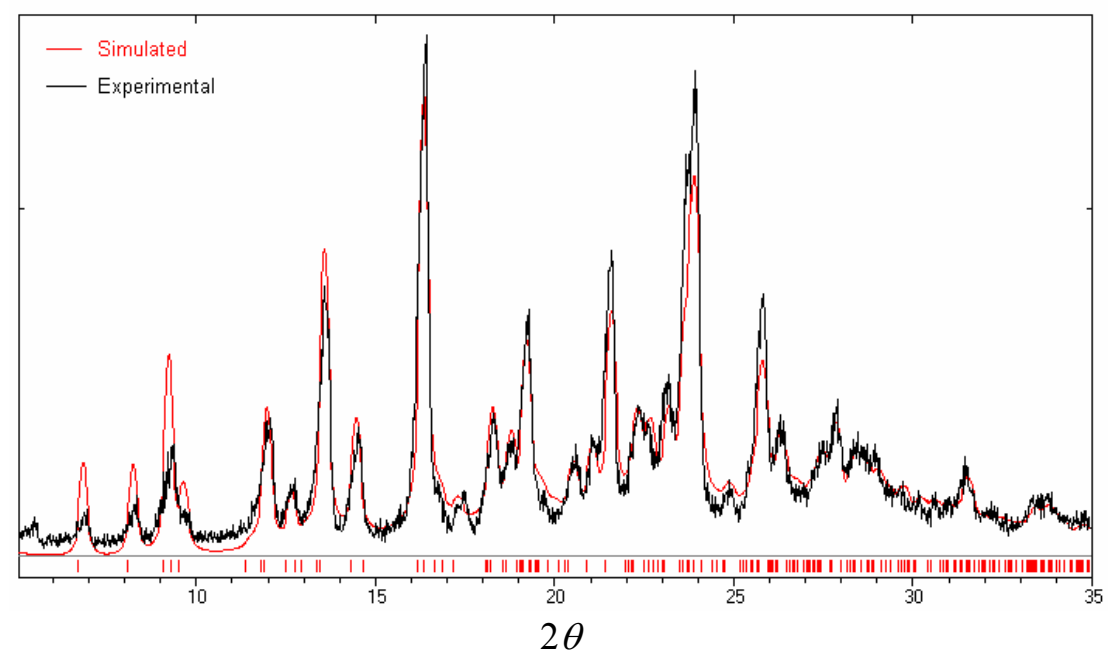

Figure 3. Experimental PXRD of SS apohost at $120^{\circ} \mathrm{C}$ (black line) matches with the calculated powder pattern of SS apohost (red line). The starting solid was a mixture of amorphous and crystalline forms. 


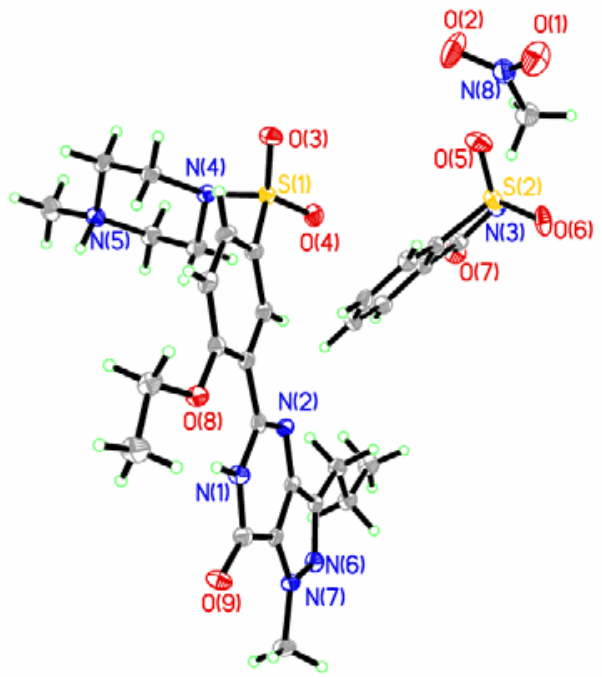

Figure 4. ORTEP diagram of nitromethane solvate of SS.

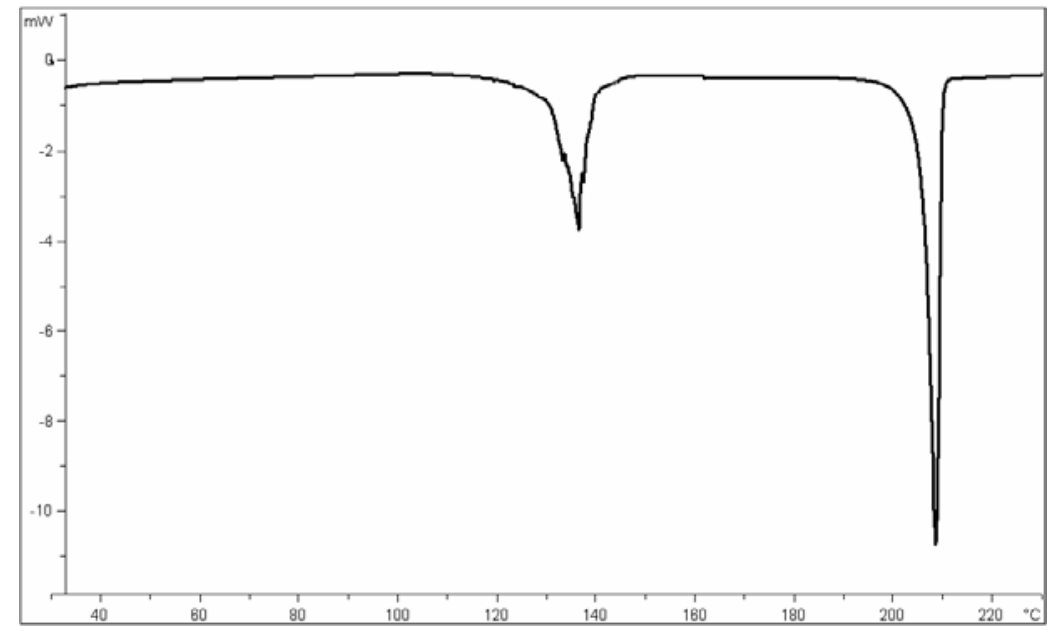

Figure 5. DSC traces of the nitromethane solvate of SS.

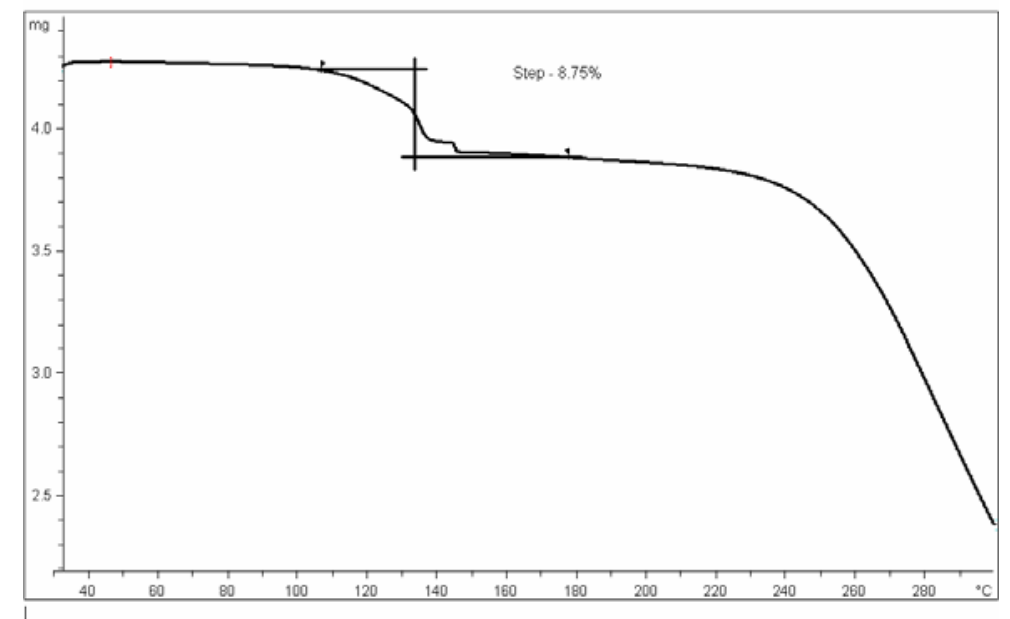

Figure 6. TGA of the nitromethane solvate of SS. 


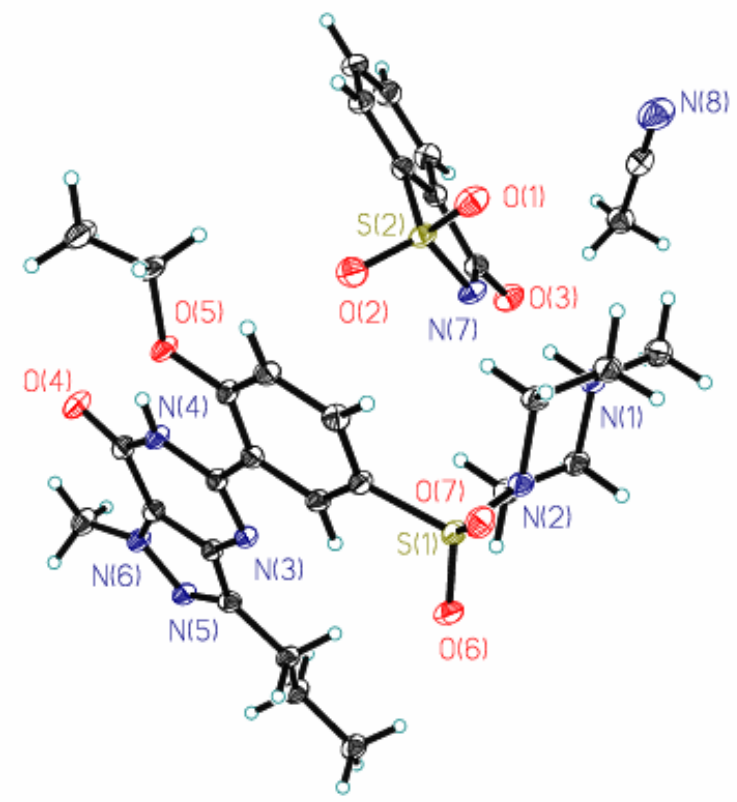

Figure 7. ORTEP diagram of acetonitrile solvate of SS.

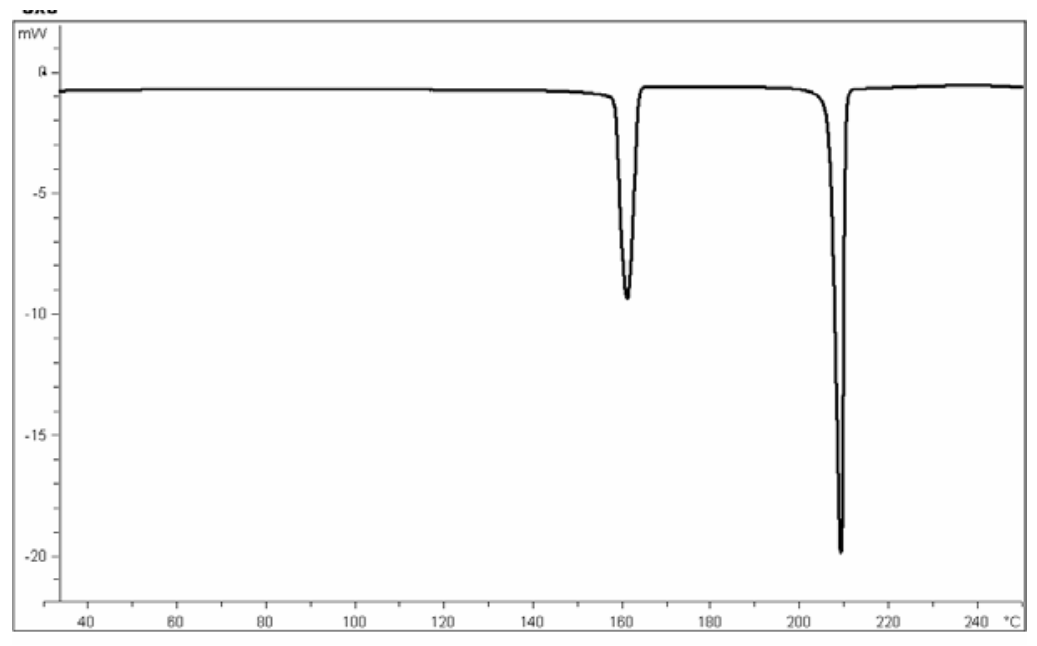

Figure 8. DSC traces of the acetonitrile solvate of SS.

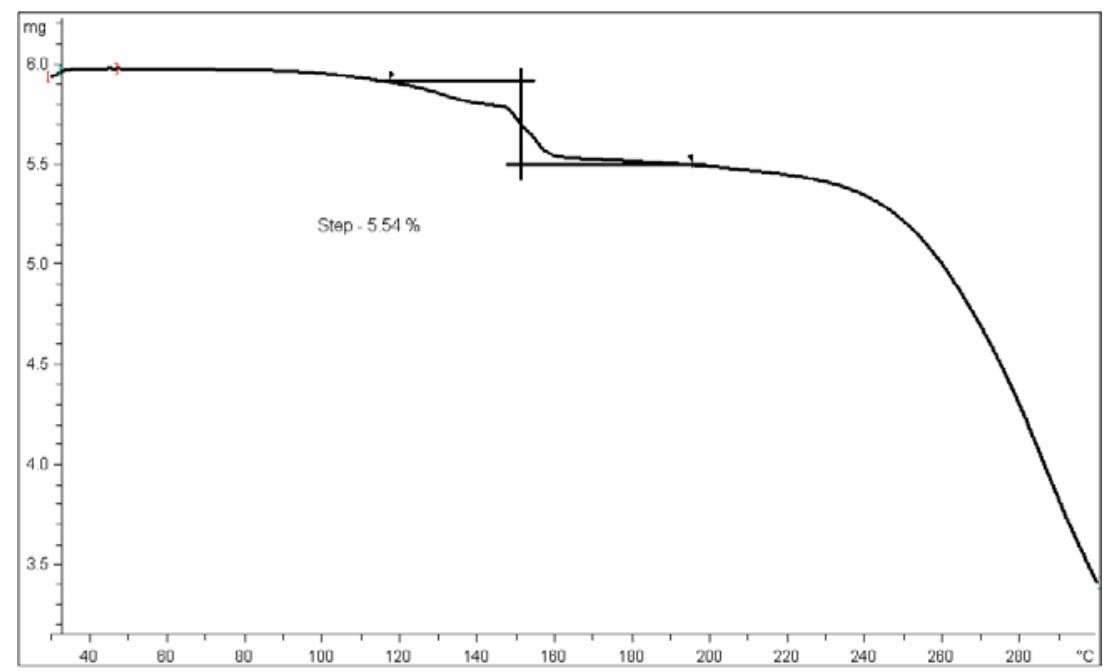

Figure 9. TGA of the acetonitrile solvate of SS. 


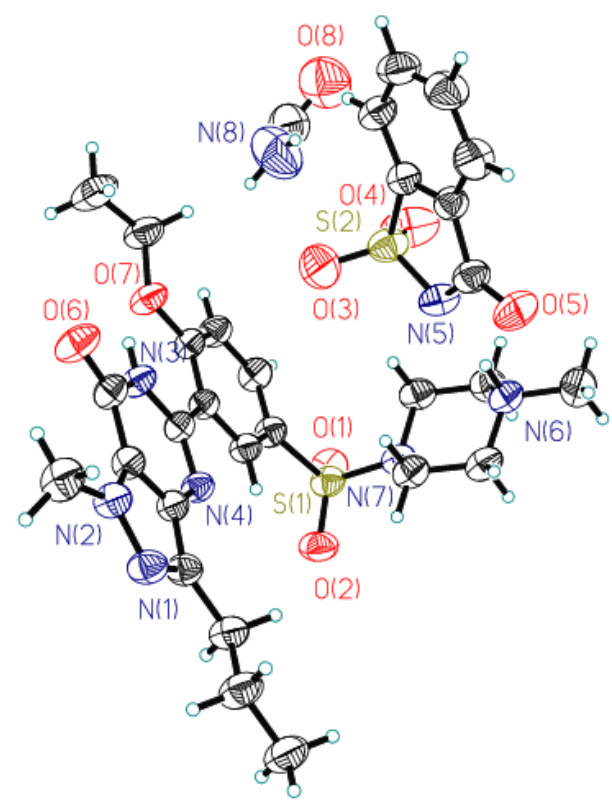

Figure 10. ORTEP diagram of formamide solvate of SS.

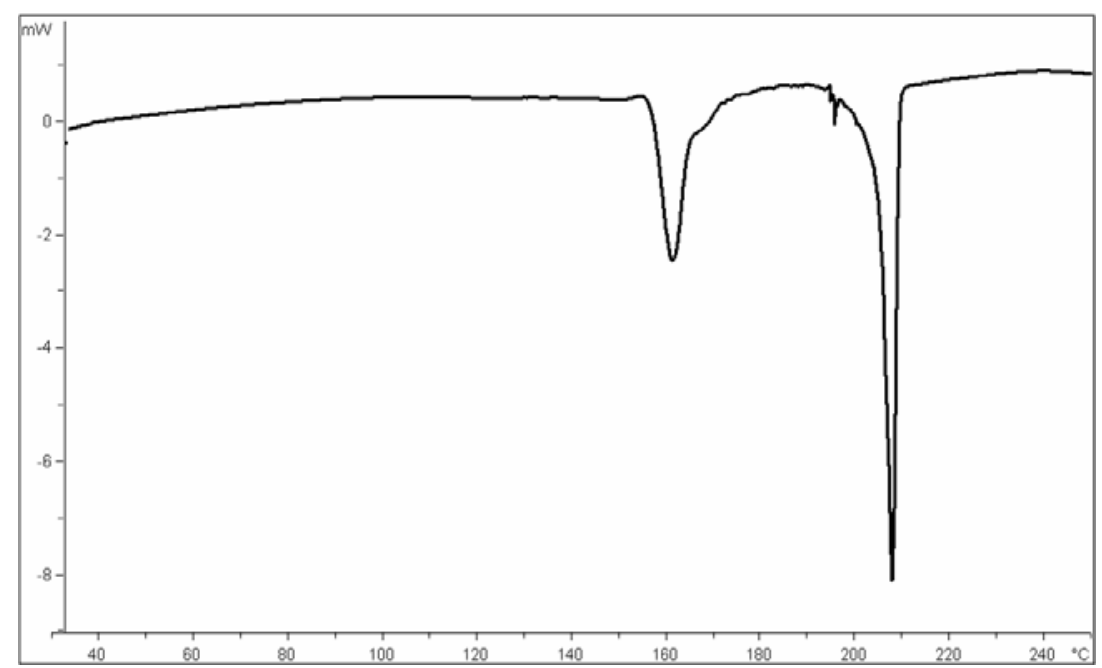

Figure 11. DSC traces of the formamide solvate of SS.

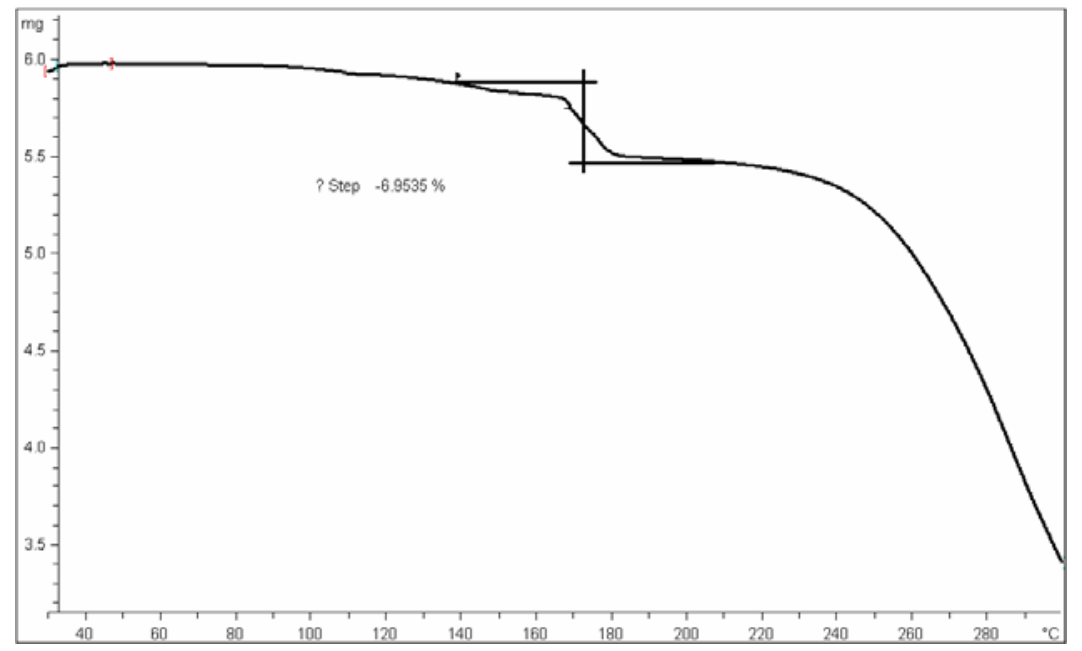

Figure 12. TGA of the formamide solvate of SS. 


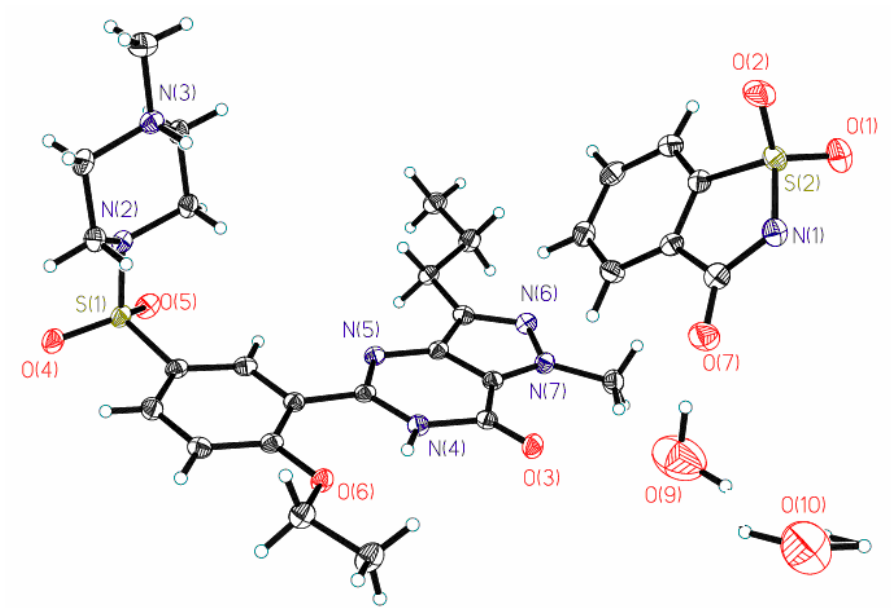

Figure 13. ORTEP diagram of SS hydrate.

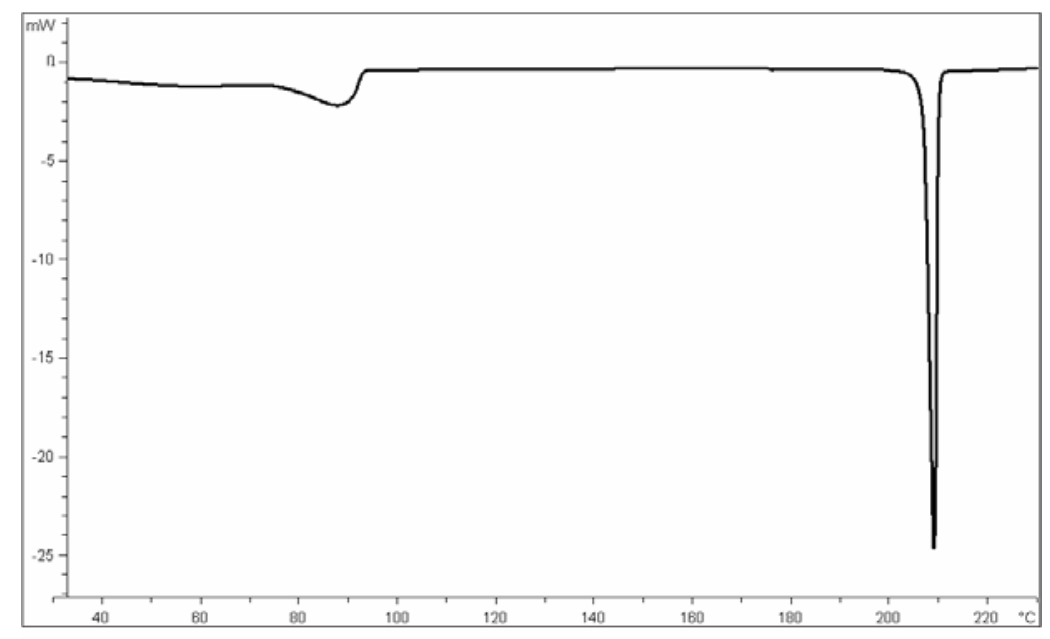

Figure 14. DSC traces of SS hydrate.

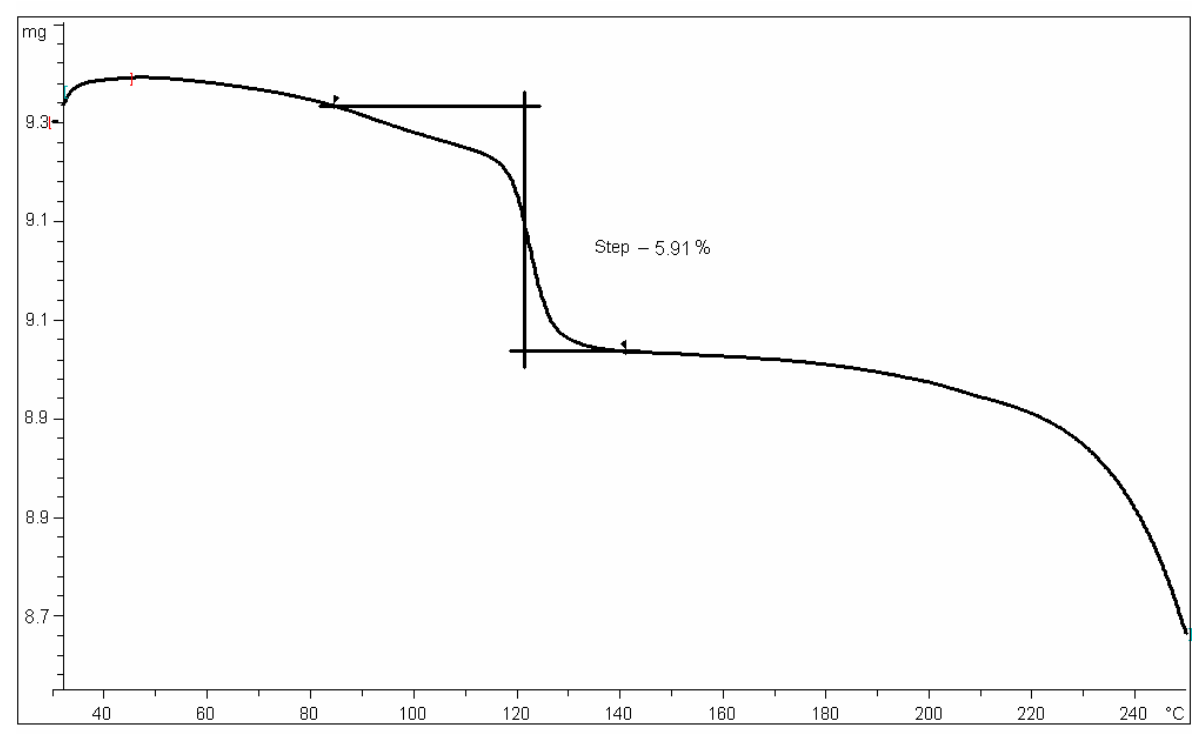

Figure 15.TGA of SS hydrate. 


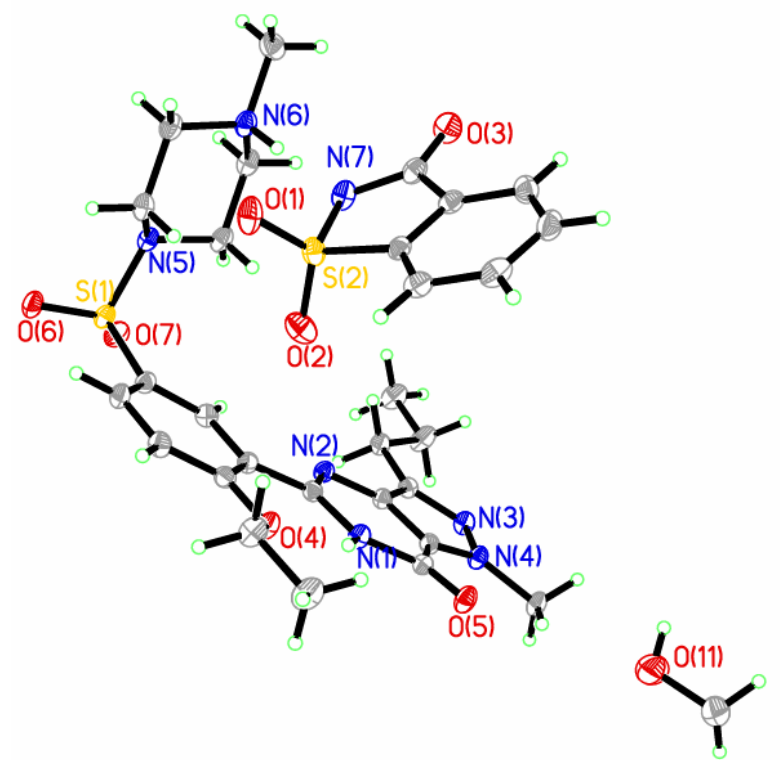

Figure 16. ORTEP diagram of ethylene glycol solvate of SS.

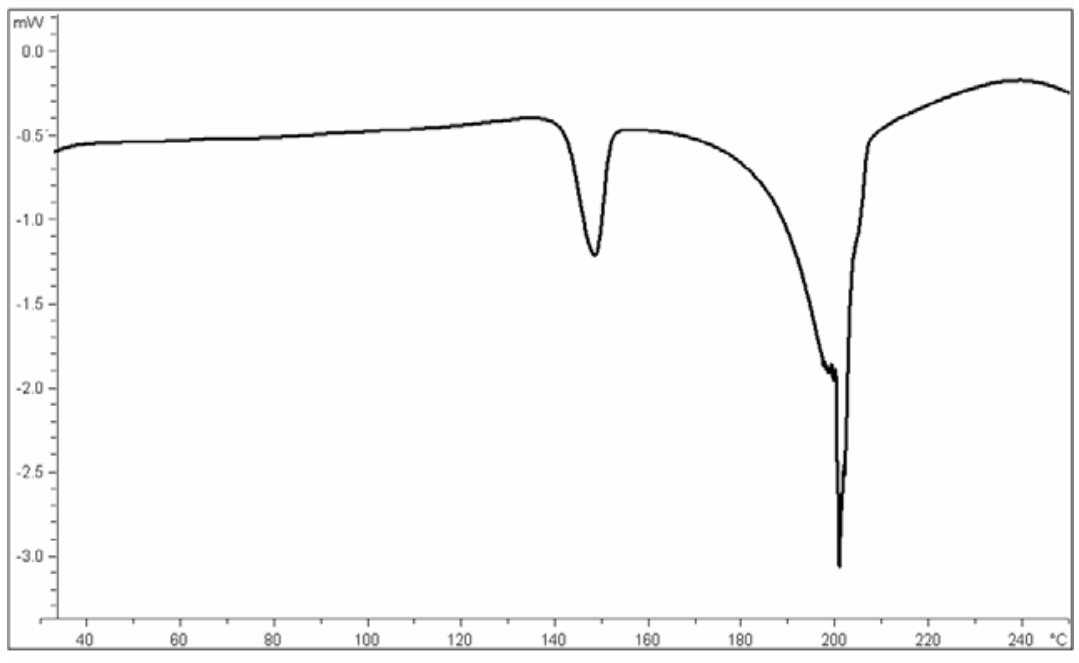

Figure 17. DSC traces of ethylene glycol solvate of SS.

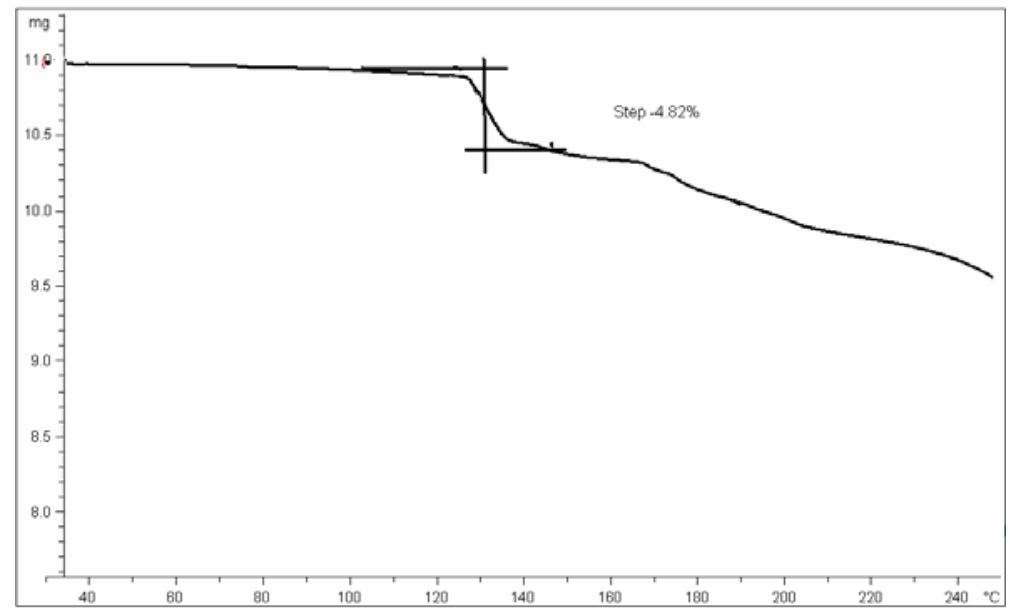

Figure 18. TGA of the ethylene glycol solvate of SS. 


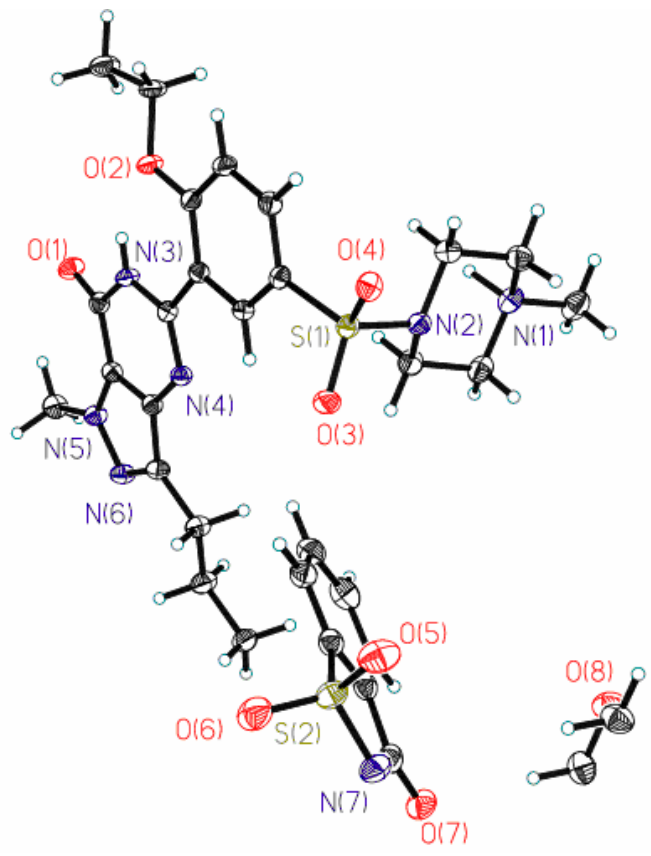

Figure 19. ORTEP diagram of 1,4 dioxane solvate of SS.

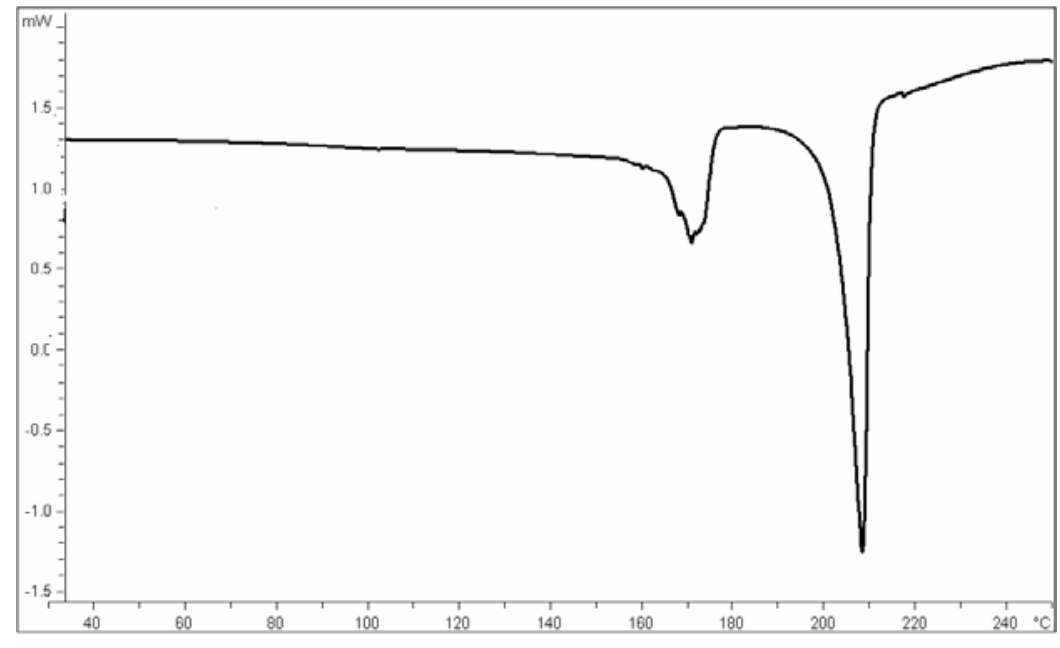

Figure 20. DSC traces of 1,4 dioxane solvate of SS.

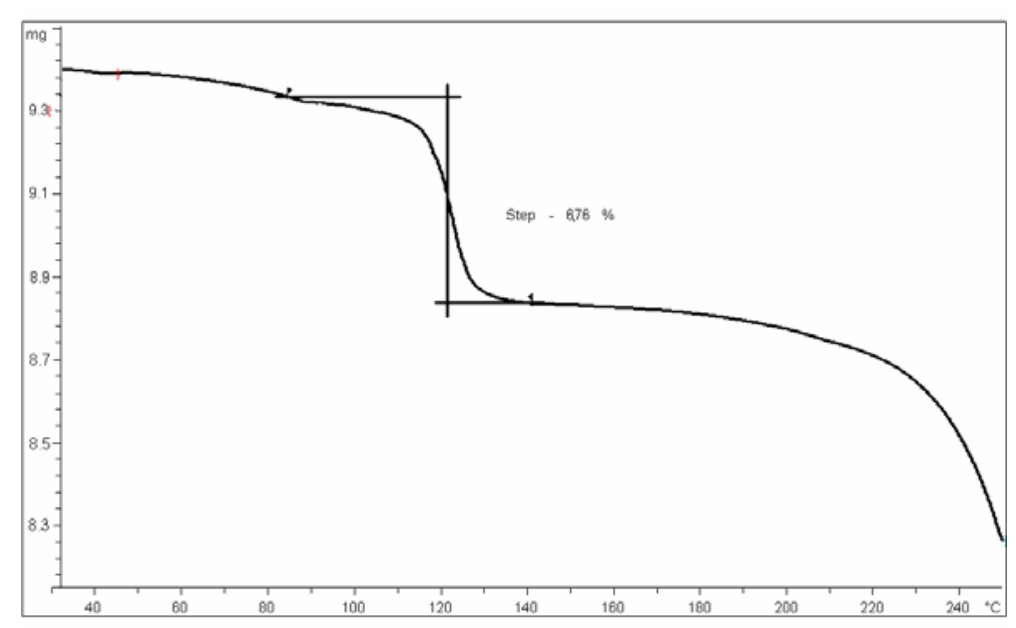

Figure 21. TGA of 1,4 dioxane solvate of SS. 


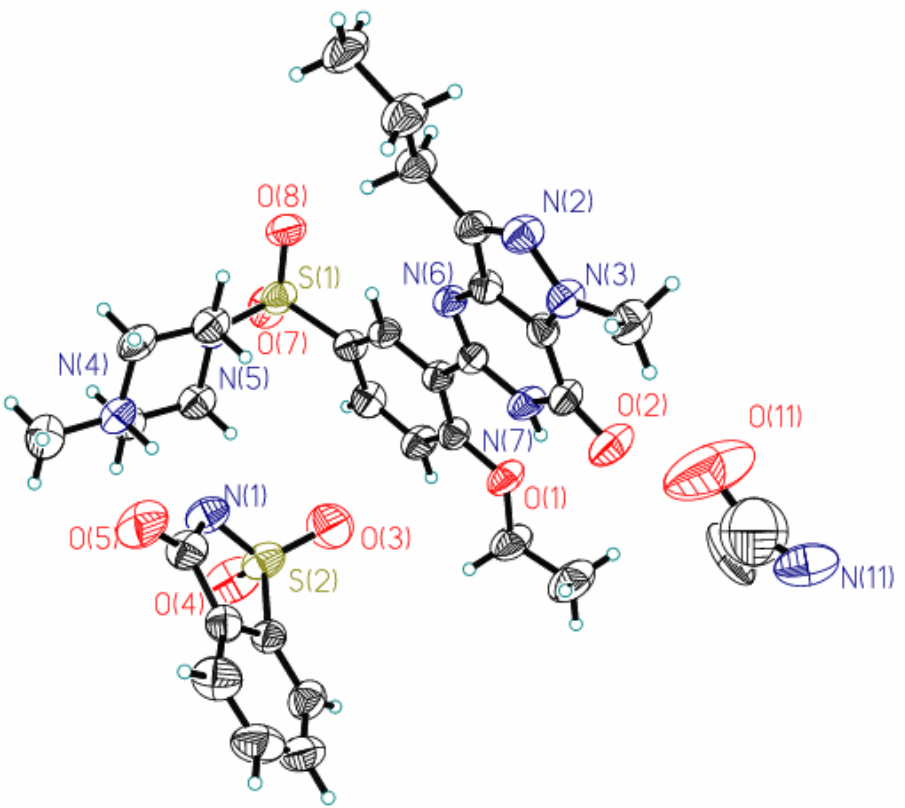

Figure 22. ORTEP diagram of pyrrolidinone solvate of SS.

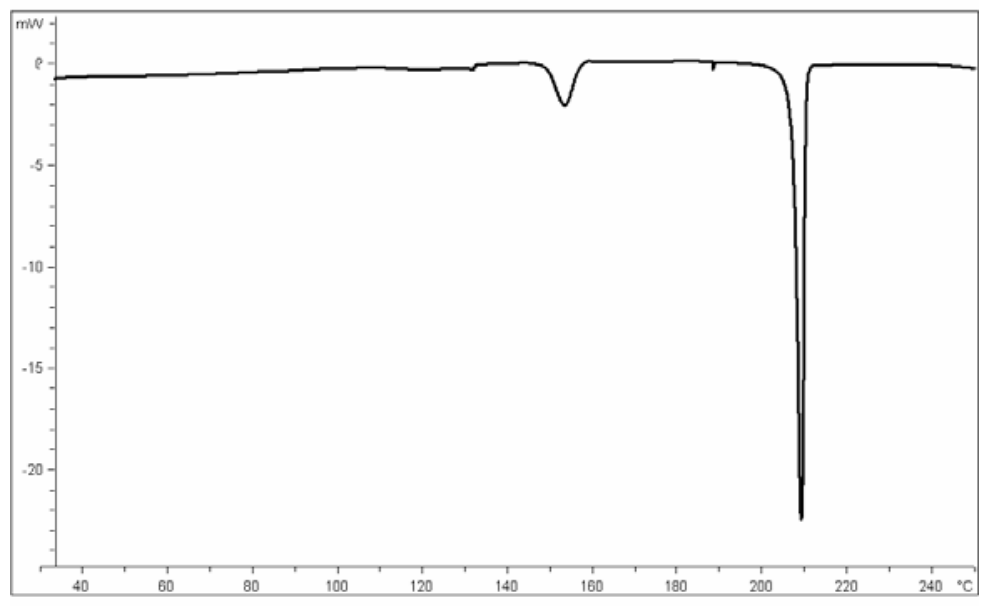

Figure 23. DSC traces of pyrrolidinone solvate of SS.

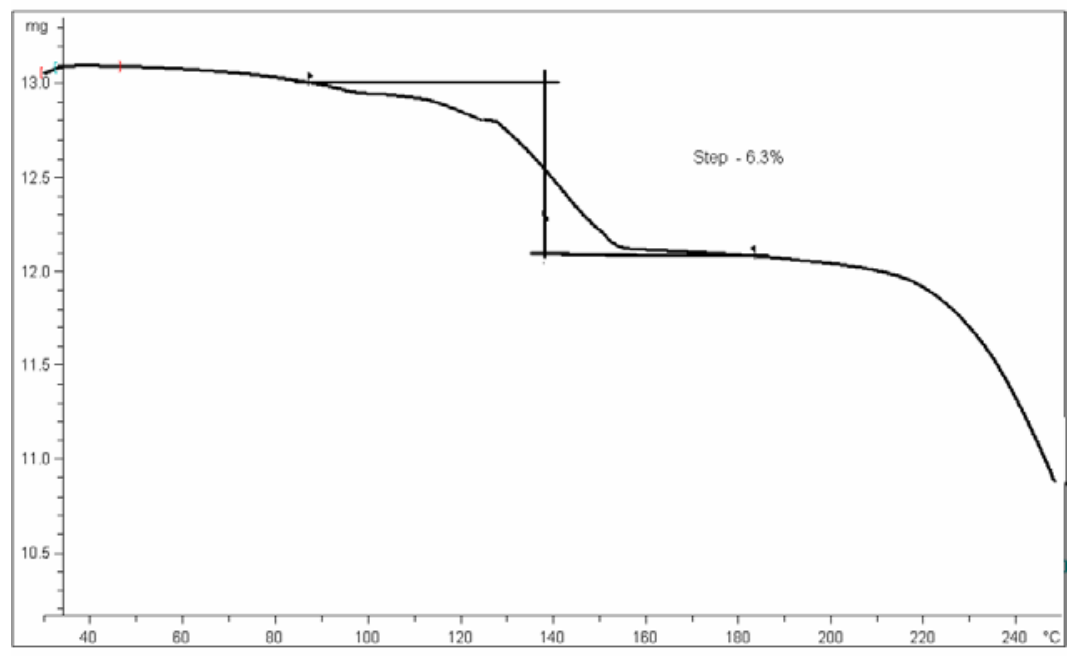

Figure 24. TGA of pyrrolidinone solvate of SS. 


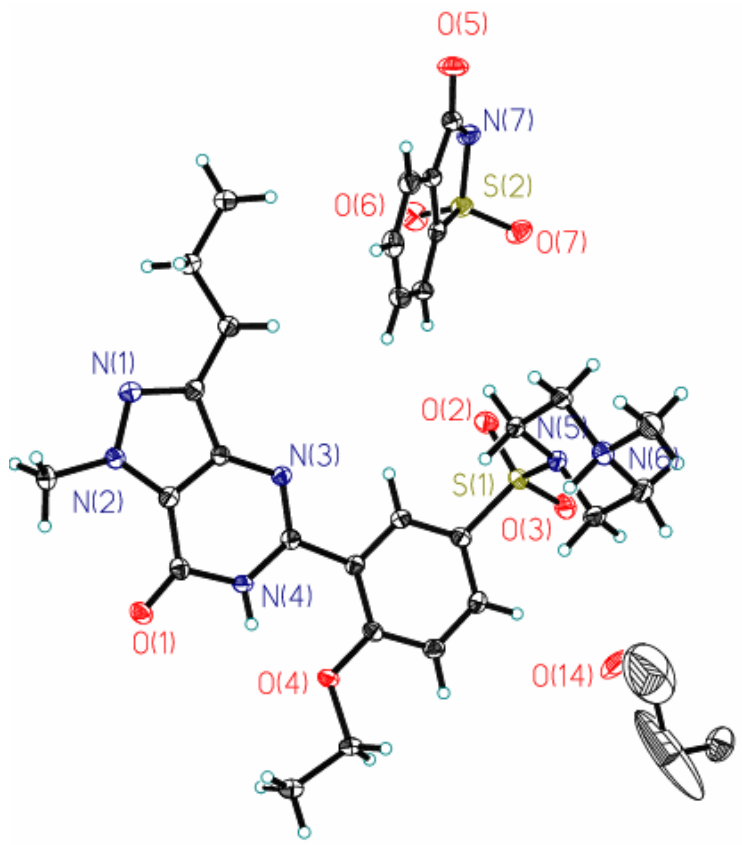

Figure 25. ORTEP diagram of ethanol solvate of SS.

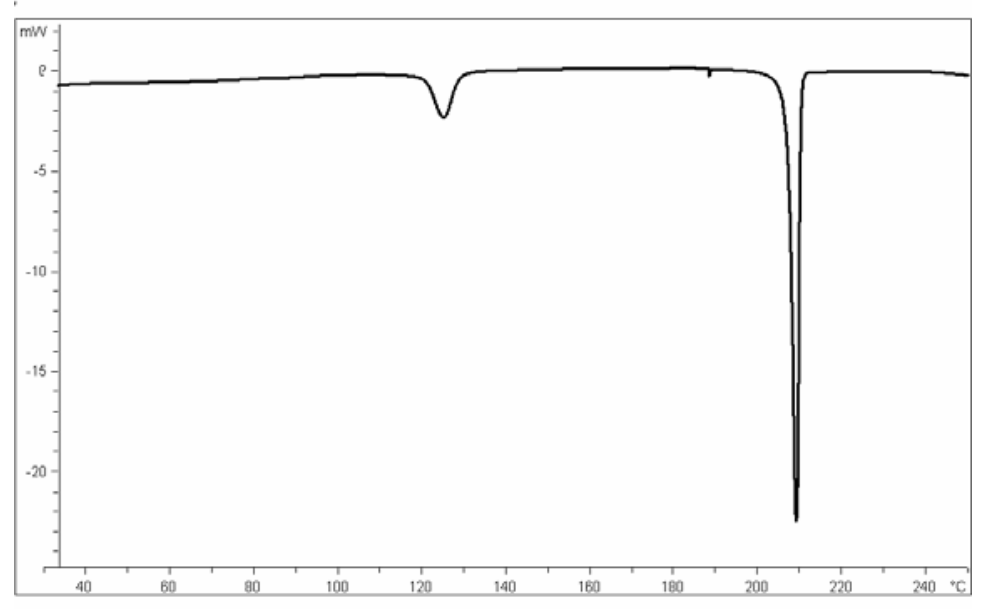

Figure 26. DSC traces of ethanol solvate of SS.

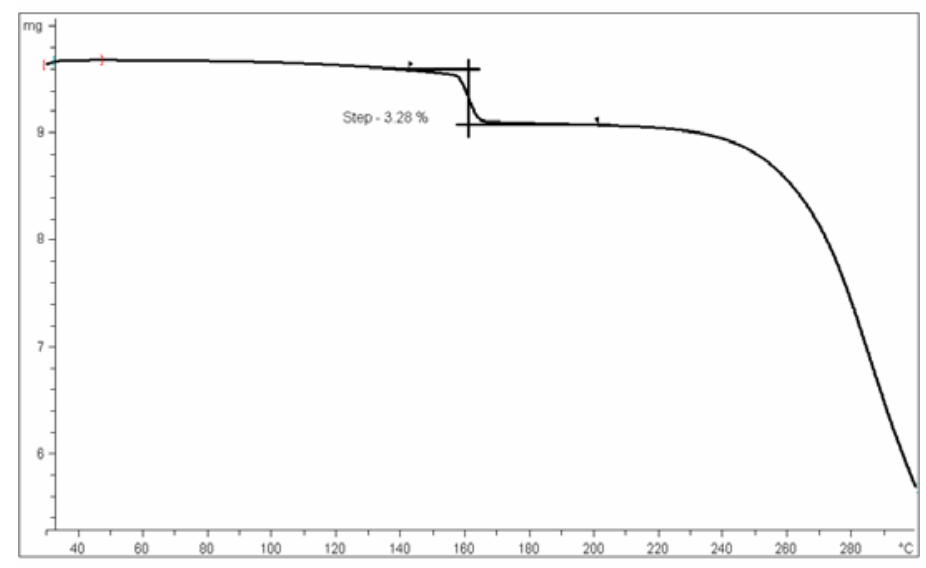

Figure 27. TGA of ethanol solvate of SS. 


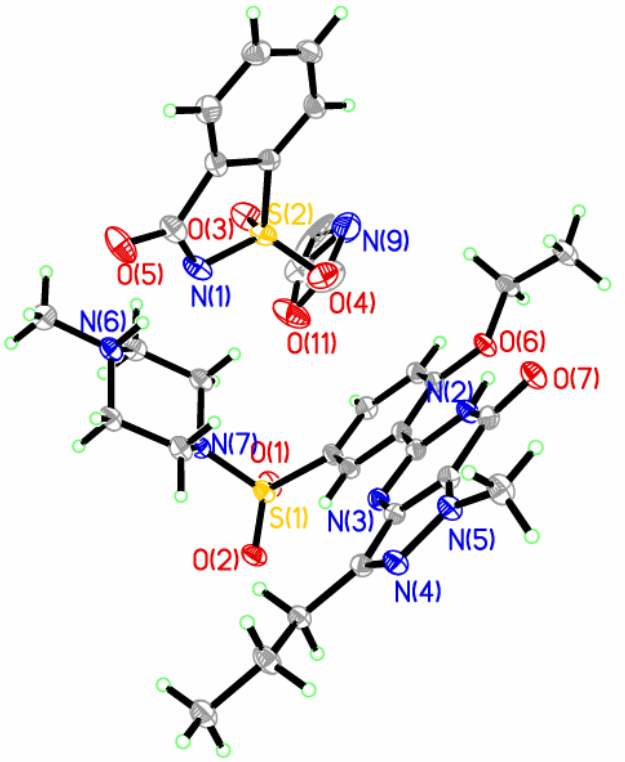

Figure 28. ORTEP diagram of DMF solvate of SS.

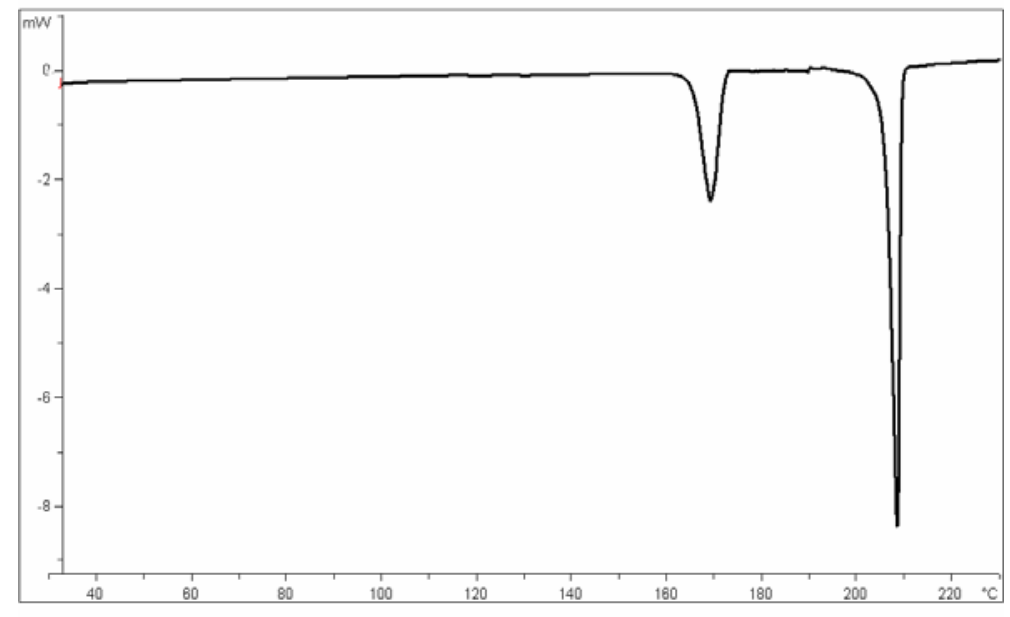

Figure 29. DSC traces of DMF solvate of SS.

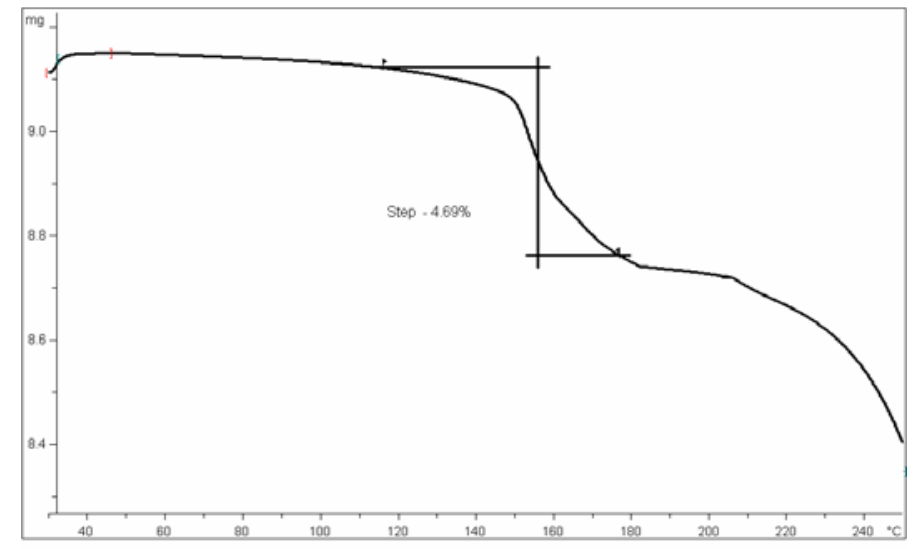

Figure 30. TGA of DMF solvate of SS. 


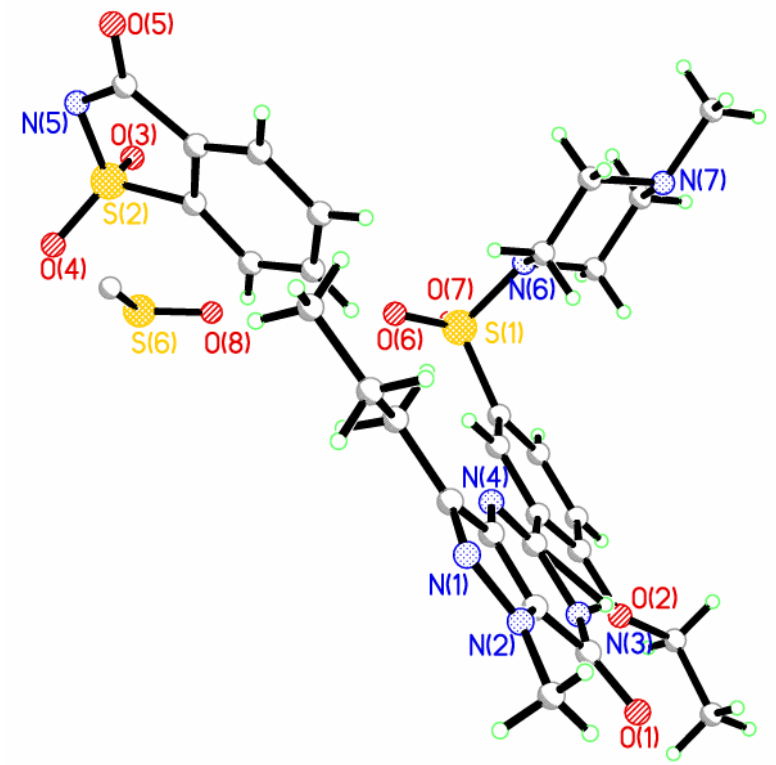

Figure 31. Diagram of DMSO solvate of SS.

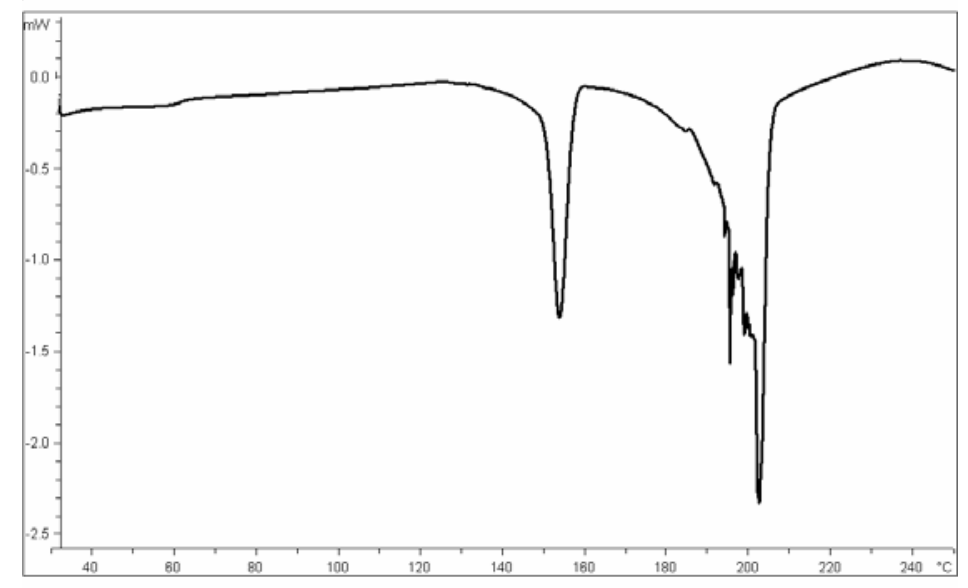

Figure 32. DSC traces of DMSO solvate of SS. Note the abnormal melting endotherm compared to the other solvates.

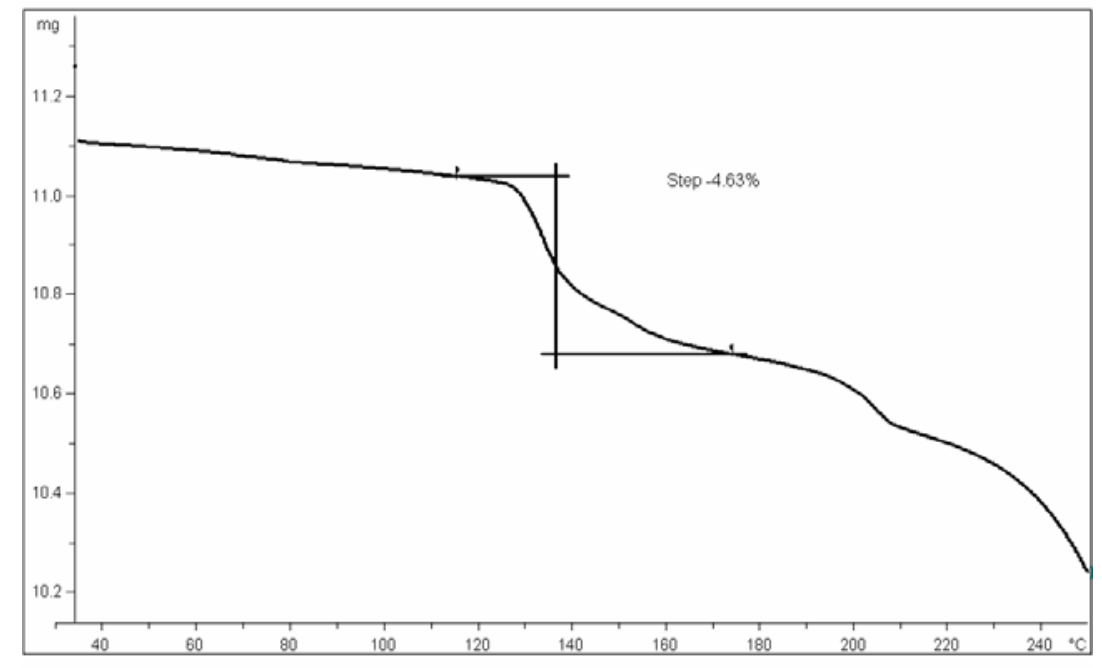

Figure 33. TGA of DMSO solvate of SS. 


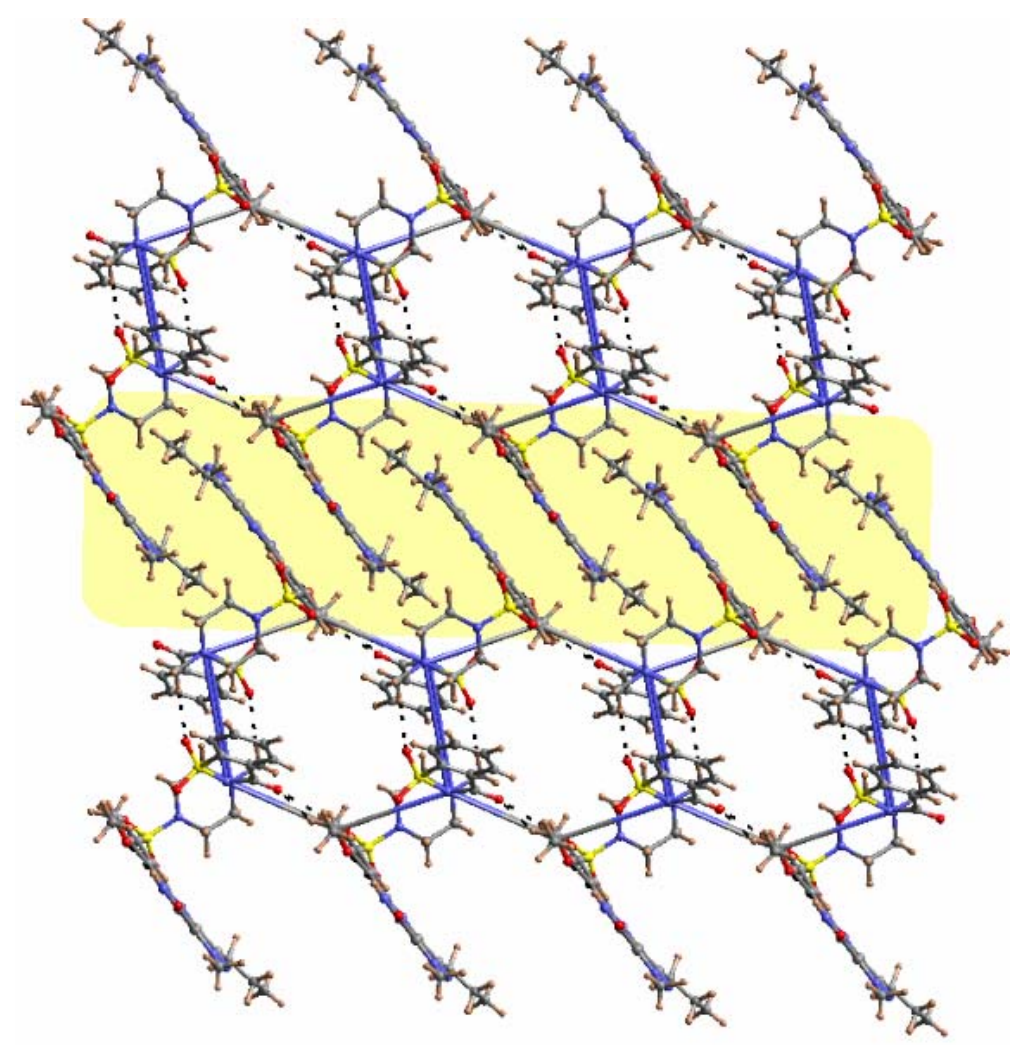

Figure 34. Hexagonal cavities in the solvates of SS viewed down the $c$-axis illustrating the overall 2-D network. The stacking region is highlighted. Guest molecules are removed to show the cavity.

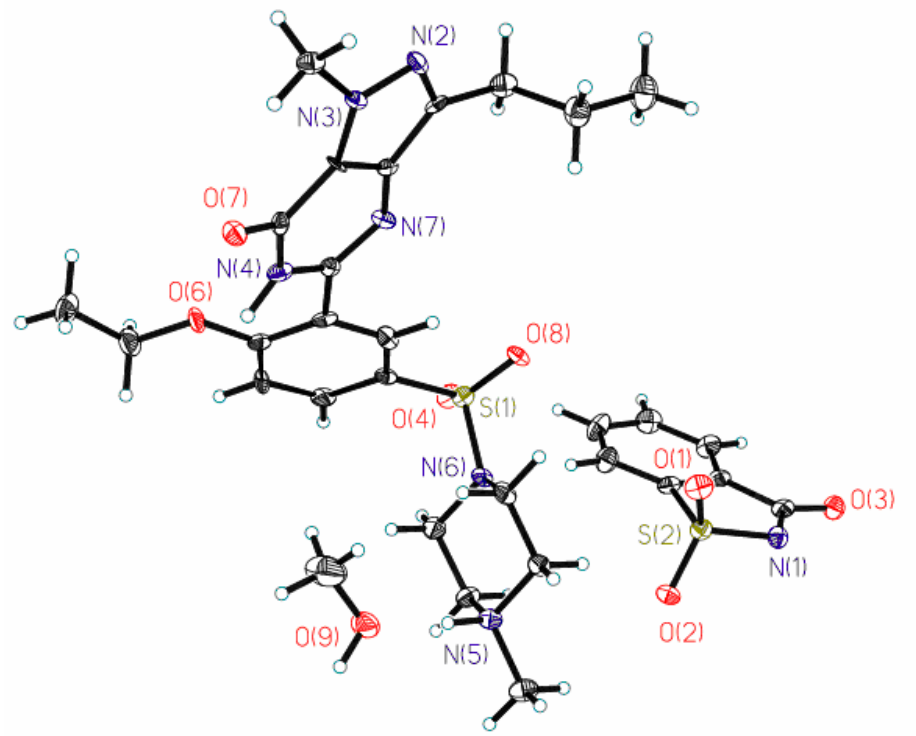

Figure 35. ORTEP diagram of sildenafil saccharinate methanolate. 
PXRD patterns of sildenafil saccharinate hydrate

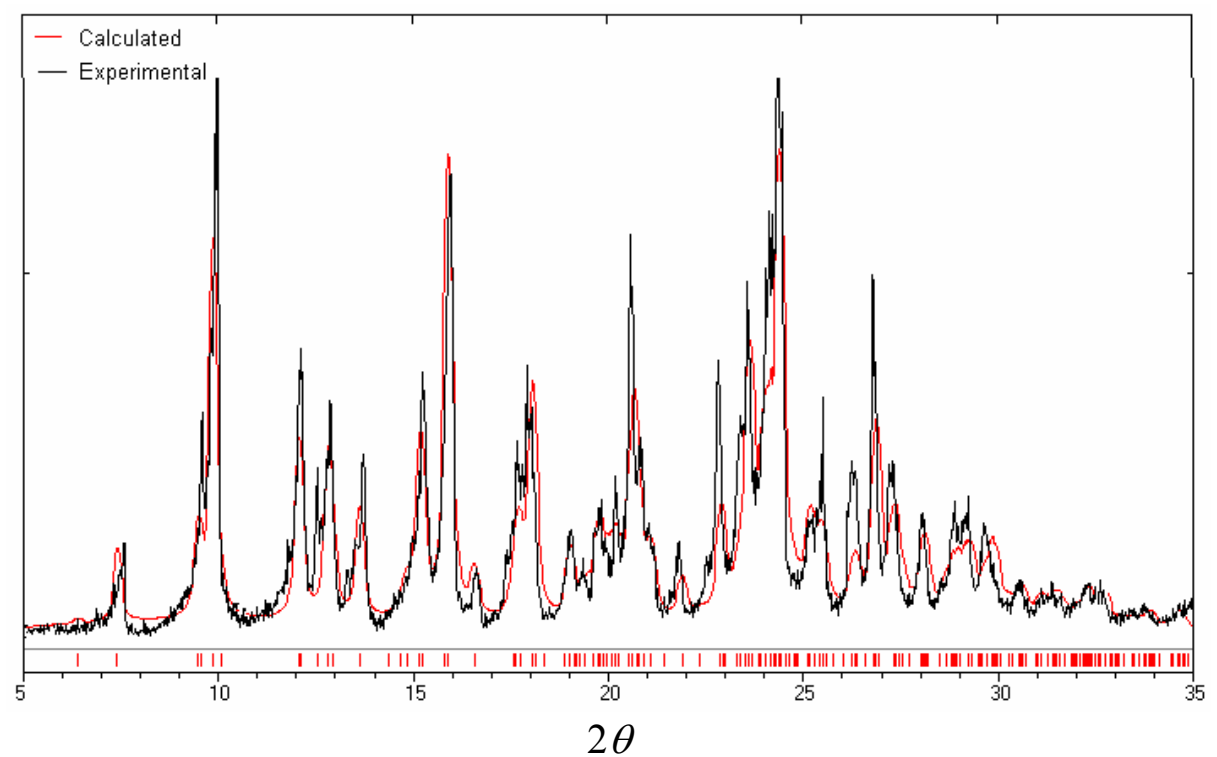

Figure 36. Experimental powder XRD of (SS). $\left(\mathrm{H}_{2} \mathrm{O}\right)_{2}$ at room temperature (black line) matches with the powder pattern calculated from the crystal structure (red line).

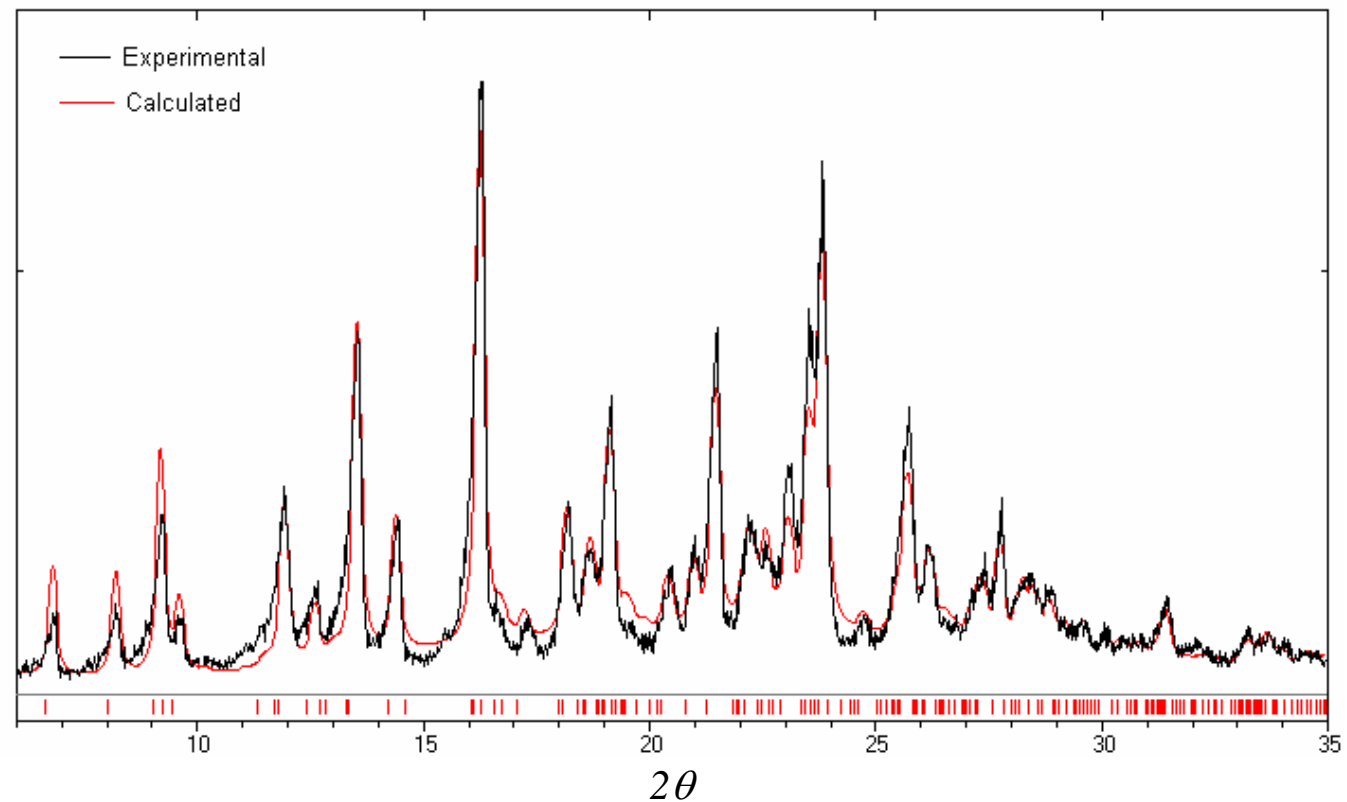

Figure 37. Experimental powder XRD of $(\mathrm{SS}) \cdot\left(\mathrm{H}_{2} \mathrm{O}\right)_{2}$, after heating the sample at $100{ }^{\circ} \mathrm{C}$ for 2 hours, (black line) matches with the calculated powder pattern of apohost (red line). 